\title{
EDITORIAL
}

\section{Hand washing - an essential protective measure in healthcare settings and in the community}

\author{
Jean Bosco Gahutu, Editor-in-Chief
}

Hand washing is one of the best practices that are taught to and applied by health professionals. Within hospitals and other healthcare facilities, it contributes to the protection of the patients and the healthcare providers in addition to the use of gloves and other personal protective equipment by the healthcare providers. The efficacy of water and soap to prevent transmission of gastrointestinal disease and to a lesser extent respiratory disease is well documented [1].

Rwandan hospitals have promoted hand washing among health professionals as part of the quality improvement and accreditation process. Emphasis is put on hand washing before and after interaction with a patient. Availability of hand washing stations, water and soap has been achieved through partnership with cleaning companies, which sign contracts with hospitals.

The healthcare personnel are taught the correct hand washing technique by applying the World Health Organization method, with help of images of all steps of hand washing posted at hand washing stations.

The hand washing measures also apply to patients and visitors for whom specific hand washing stations are foreseen. Respect of the hand washing procedures not only protects the patients and the healthcare providers but also the community at large thanks to the requirement for hand washing before leaving the hospital.
The quality improvement and accreditation process that is going on in Rwandan hospitals is proving to be a proactive strategy. Indeed, as the COVID-19 pandemic has expanded worldwide, strict protective measures need to be scrupulously followed for the protection of the patients, the health professionals and the community.

One of the most important measures against the COVID-19 pandemic is hand washing. Indeed, water and soap can prevent the spread of coronaviruses, which do not resist biocidal agents [2]. Disinfection of all surfaces and hand washing constitute a strategy of utmost importance in the prevention of COVID-19. The urgent need for hand washing found the Rwandan population well prepared, not only in hospitals but also at other public and private places. Full adherence is a requirement for the fight against the pandemic. Most important is good health education of the population to understand the necessity for full compliance with hygiene measures to fight the pandemic.

\section{REFERENCES}

1. Aiello AE, Coulborn RM, Perez V, Larson EL. Effect of hand hygiene on infectious disease risk in the community setting: a meta-analysis. Am J Public Health 2008;98(8):1372-1381.

2. Kampf G, Todt D, Pfaender S, Steinmann E. Persistence of coronaviruses on inanimate surfaces and their inactivation with biocidal agents. J Hospital Infection 2020;104:246-251. 